\title{
Kraft Lignin Ethanolysis over Zeolites with Different Acidity and Pore Structures for Aromatics Production
}

\author{
Nathan Cody Baxter ${ }^{1}$, Yuxin Wang ${ }^{1}$, Huijiang Huang ${ }^{2}$, Yixin Liao ${ }^{1}$, Heath Barnett ${ }^{3}$, Yujun Zhao ${ }^{2, *}$ and \\ Shengnian Wang $1, *$ (D)
}

1 Chemical Engineering, Institute for Micromanufacturing, Louisiana Tech University, 911 Hergot Avenue, Ruston, LA 71272, USA; nbaxt000@hotmail.com (N.C.B.); w-yuxin@hotmail.com (Y.W.); yli029@latech.edu (Y.L.)

2 School of Chemical Engineering and Technology, Tianjin University, Tianjin 300072, China; hhjiang@tju.edu.cn

3 Chemistry, School of Science, University of Louisiana at Monroe, 700 University Ave, Monroe, LA 71209, USA; hbarnett@ulm.edu

* Correspondence: yujunzhao@tju.edu.cn (Y.Z.); swang@latech.edu (S.W.); Tel.: +86-022-87401818 (Y.Z.); $+1-318-257-5125$ (S.W.)

check for updates

Citation: Baxter, N.C.; Wang, Y.; Huang, H.; Liao, Y.; Barnett, H.; Zhao, Y.; Wang, S. Kraft Lignin Ethanolysis over Zeolites with Different Acidity and Pore Structures for Aromatics Production. Catalysts 2021, 11, 270. https://doi.org/10.3390/catal11020270

Academic Editor: Valery E. Tarabanko

Received: 17 January 2021

Accepted: 15 February 2021

Published: 18 February 2021

Publisher's Note: MDPI stays neutral with regard to jurisdictional claims in published maps and institutional affiliations.

Copyright: (c) 2021 by the authors. Licensee MDPI, Basel, Switzerland. This article is an open access article distributed under the terms and conditions of the Creative Commons Attribution (CC BY) license (https:// creativecommons.org/licenses/by/ $4.0 /)$.

\begin{abstract}
To utilize its rich aromatics, lignin, a high-volume waste and environmental hazard, was depolymerized in supercritical ethanol over various zeolites types with different acidity and pore structures. Targeting at high yield/selectivity of aromatics such as phenols, microporous Beta, Y, and ZSM-5 zeolites were first examined in lignin ethanolysis, followed by zeolites with similar micropore size but different acidity. Further comparisons were made between zeolites with fin-like and worm-like mesoporous structures and their microporous counterparts. Despite depolymerization complexity and diversified ethanolysis products, strong acidity was found effective to cleave both $\mathrm{C}-\mathrm{O}-\mathrm{C}$ and $\mathrm{C}-\mathrm{C}$ linkages of lignin while mild acidity works mainly in ether bond breakdown. However, when diffusion of gigantic molecules is severe, pore size, particularly mesopores, becomes more decisive on phenol selectivity. These findings provide important guidelines on future selection and design of zeolites with appropriate acidity and pore structure to promote lignin ethanolysis or other hydrocarbon cracking processes.
\end{abstract}

Keywords: zeolites; lignin depolymerization; mesoporous materials; acidity; supercritical ethanol; fin-like mesopores

\section{Introduction}

Lignin is a mixture of natural polyaromatics with several basic phenol units (i.e., coumaryl, coniferyl, and sinapyl) randomly while repeatedly cross-linked with ether and C-C linkages [1]. Contributing $20-40 \mathrm{wt} \%$ of mass and $\sim 40 \%$ of the heating value of biomass, lignin, however, has long been a high-volume by-product and environmental hazard of paper and pulp plants. With a globule production of $\sim 150$ billion pounds/year, $\sim 98 \%$ lignin is exclusively burned for simply heating [2]. Depolymerization of lignin may not only mitigate such waste and pollution, but also generate profit by producing feedstock towards high-value aromatics and/or high-quality fuels [3]. Progress has been made in lignin depolymerization by processes like hydrolysis, ethanolysis, hydrogenolysis, or thermal cracking to release its rich phenol-type aromatics [4-12]. Compared to liquid solvents, supercritical ethanol is found to allow high solubility of lignin and the produced organic compounds, and more important, provide rich hydrogen radicals to couple with intermediate products during lignin depolymerization to prevent their further condensation reactions [13]. Catalysts have been introduced to help improve the cleavage efficiency of $\mathrm{C}-\mathrm{O}-\mathrm{C}$ and $\mathrm{C}-\mathrm{C}$ linkages of lignin as well as the yield or selectivity of its diverse products [14-21]. Further studies found that the physical and chemical properties of these catalysts, namely their various acidity and pore structures, play important roles on 
lignin depolymerization [22-25]. Similar to what happens in traditional cracking processes for fossil fuel, zeolites are widely used in lignin depolymerization, serving either as catalyst or catalytic support [25-32]. Their tailorable acidity and uniform pore size gain them popularity on achieving good cracking efficiency and/or product selectivity. However, sole micropore structure of traditional zeolites $(<2 \mathrm{~nm}$ in diameter) defined by their unique crystal framework makes the diffusion of gigantic molecules such as lignin fragments, their oligomers, or even some decomposed monomers difficult, resulting in quick pore blocking, coke formation, and catalyst deactivation [33]. Although the regeneration of zeolites is relatively convenient when compared to transition metal catalysts and their reuse is mature owing to their wide applications in oil refinery processes, introducing mesopores $(2-50 \mathrm{~nm}$ in diameter) or staged hierarchical porosity (i.e., connected macropores, mesopores, and micropores) is considered a promising long-term solution to overcome such limited molecule transport challenges and low active site utilization issues for zeolites in both traditional petrochemical processes and the emerging bio-energy processes like lignin depolymerization [34-40]. Although either lignin ethanolysis or catalytic cracking using mesoporous zeolites have been extensively studied separately, combing the merits of these two strategies for their synergetic potentials is yet examined. Hence, we investigated catalytic lignin depolymerization under supercritical ethanol (scEtOH) with zeolites of various solid acidity and porous structures. With benefits of high lignin conversion, high liquid product yield, and minimum char formation from ethanolysis of lignin [1], we evaluate appropriate architectures and chemistry of zeolites towards favorable aromatics production. Our comparisons were made not only among the same types of zeolites with either their pore structure or acidity difference singled out (i.e., mesoporous zeolites versus their microporous counterparts, and the same zeolite crystals with different acidity caused by various ion-exchange levels), but also various types of zeolites with these features (i.e., pore size or acidity) presented in a more complicated manner. Three H-type, different zeolites with exclusive micropores, HZSM-5, HY, and HBeta, were evaluated, given the first two carry significant differences on both micropore size (HZSM-5: $5.6 \times 5.3 \AA$, $5.5 \times 5.1 \AA$; HY: $7.4 \times 7.4 \AA$ ) and acidic site ratios while HBeta shares one of these two important features with HZSM-5 and HY, respectively, as shown schematically in Figure 1a. The contribution of mesopore architectures, including fin-like and worm-like mesoporous structure in zeolites, was also investigated to reveal their important roles on bond cleavage within lignin during scEtOH depolymerization (Figure 1b).

(a)

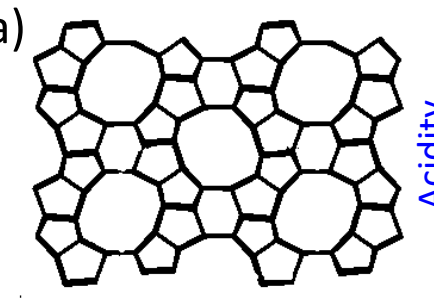

ZSM-5 $(5.6 \times 5.3,5.5 \times 5.1 \AA ̊)$

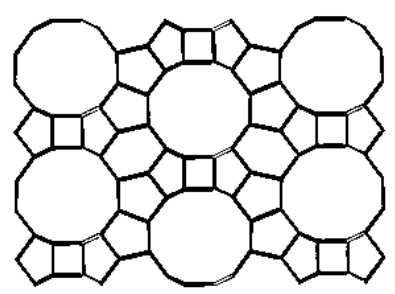

HBeta $(7.7 \times 6.6,5.6 \times 5.6 \AA)$
Micropore size

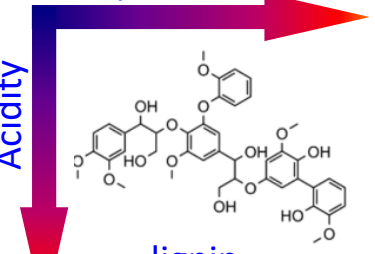

lignin

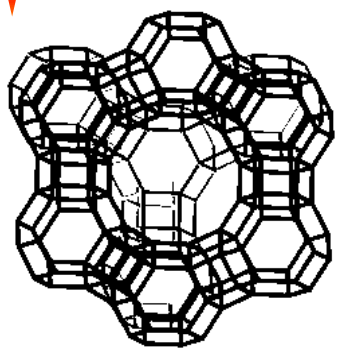

HY $(7.4 \times 7.4 \AA ̊)$ (b)

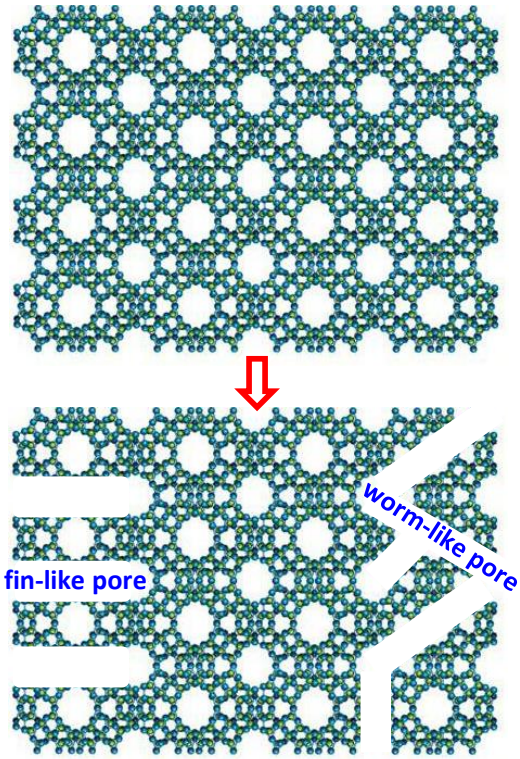

Figure 1. Schematics of zeolites of different acidity and pore structures used for lignin depolymerization in supercritical ethanol. (a) The framework of ZSM-5, Beta, and USY zeolites and (b) a combination of micropore and mesopore (including fin-like pore and worm-like pore) structures. 


\section{Results}

\subsection{Morphology and Textural Properties of Zeolites Used in Lignin Depolymerisation}

The texture properties of different types of zeolites used for lignin depolymerization in supercritical ethanol were characterized with SEM, XRD, and Pore Size Analyzer. As a result of their similar synthesis receipts, similar elongated, hexagonal plate shape with an average dimension of $\sim 225 \times 500 \times 700 \mathrm{~nm}$ was obtained for both microporous ZSM-5 and mesoporous ZSM- 5 zeolites, as shown in Figure 2a,b. Rather than conventional microporous ZSM- 5 zeolites that exhibit smooth surface on each axis direction, the morphology of mesoporous ZSM-5 obtained with the assistance of dual meso-templates is quite different. Multiple laminar structures are shown in the a-axis direction of mesoporous ZSM-5 zeolites which are fused together on one end of the b-axis framework into a large monolithic piece to create many fin-like mesoscale space besides obvious macropores (Figure $2 b$ ). The XRD patterns of mesoporous ZSM- 5 and common microporous ZSM- 5 samples show identical, well-resolved peaks which belong to MFI zeolite structure (Figure 2c). This confirms the successful synthesis of ZSM- 5 with this new fin-like mesoporous structure (denoted as FM-ZSM-5 in later discussions). Their different pore structures are further confirmed through the $\mathrm{N}_{2}$ adsorption-desorption isotherms. As shown in Figure $2 \mathrm{~d}$, conventional microporous ZSM-5 presents a classic type I adsorption/desorption isotherm for microporous materials, which has only one high uptake at very low relative pressure $\left(\mathrm{P} / \mathrm{P}_{0}<0.02\right)$, a slight increase in the isotherm slope in the low-pressure range $\left(0.02<\mathrm{P} / \mathrm{P}_{0}<0.2\right)$, and a long plateau afterwards (up to 0.9$)$, indicating that the material is a purely microporous phase with little mesoporosity. On the contrary, FM-ZSM- 5 zeolites present a combination of both type I and type IV(a) adsorption/desorption profiles with multiple uptake steps: a steep one $\left(\mathrm{P} / \mathrm{P}_{0}<0.02\right)$, an obvious one $\left(0.02<\mathrm{P} / \mathrm{P}_{0}<0.45\right)$, and a shallow one $\left(0.45<\mathrm{P} / \mathrm{P}_{0}<0.90\right)$, responding for the filling of micropores, mesopores, and capillary condensation, respectively (Figure $2 \mathrm{~d}$ ). The disappearance of hysteresis loop on the adsorption-desorption isotherms of typical mesoporous materials at high relative pressure further suggests the existing of uniform, one end open, fin-like mesopore structure in this new FM-ZSM-5 zeolite. The textural parameters (Table 1) further reveal that FM-ZSM-5 has evidentially larger BET (Brunauer, Emmett and Teller) surface area $\left(460.3 \mathrm{~m}^{2} / \mathrm{g}\right.$ vs. $\left.354.3 \mathrm{~m}^{2} / \mathrm{g}\right)$, larger pore volume $\left(0.32 \mathrm{~cm}^{3} / \mathrm{g}\right.$ vs. $\left.0.24 \mathrm{~cm}^{3} / \mathrm{g}\right)$, and larger average BJH (Barrett, Joyner, and Halenda) pore size ( $3.6 \mathrm{~nm}$ vs. $2.7 \mathrm{~nm}$ ) when compared to its microporous counterpart. Although the use of traditional BET approach to extract surface area and pore volume information contributed by micropores from $\mathrm{N}_{2}$ adsorptiondesorption isotherms has known flaws for most zeolites, such results serve as valuable reference in comparison.

Table 1. Textural properties of microporous and mesoporous HY and HZSM-5 zeolites.

\begin{tabular}{|c|c|c|c|c|c|c|c|}
\hline Sample & $\begin{array}{c}\mathrm{S}_{\mathrm{BET}} \\
\left(\mathrm{m}^{2} / \mathrm{g}\right)\end{array}$ & $\begin{array}{c}S_{\text {micro }}{ }^{a} \\
\left(\mathrm{~m}^{2} / g\right)\end{array}$ & $\begin{array}{l}S_{\text {ext }}{ }^{a} \\
\left(\mathrm{~m}^{2} / \mathrm{g}\right)\end{array}$ & $\begin{array}{l}V_{\text {total }} b \\
\left(\mathrm{~cm}^{3} / \mathrm{g}\right)\end{array}$ & $\begin{array}{l}V_{\text {Micro }} b \\
\left(\mathrm{~cm}^{3} / \mathrm{g}\right)\end{array}$ & $\begin{array}{l}V_{\text {Meso }} b \\
\left(\mathrm{~cm}^{3} / \mathrm{g}\right)\end{array}$ & $\begin{array}{l}\text { Pore Size } \\
\text { (nm) }\end{array}$ \\
\hline HZSM-5 & 354.3 & 222.2 & 132.2 & 0.24 & 0.08 & 0.16 & 2.7 \\
\hline Meso-HZSM-5 & 460.3 & 87.8 & 372.5 & 0.32 & 0.03 & 0.29 & 3.6 \\
\hline HY & 720.6 & 566.1 & 154.5 & 0.33 & 0.21 & 0.07 & 2.6 \\
\hline Meso-HY & 766.3 & 410.5 & 355.8 & 0.50 & 0.15 & 0.22 & 6.9 \\
\hline HBeta & 536.4 & 436.2 & 100.2 & 0.37 & 0.17 & 0.20 & 2.8 \\
\hline
\end{tabular}

${ }^{a}$ t-Plot micropore area; ${ }^{\mathrm{b}}$ single point total pore volume at $\mathrm{P} / \mathrm{P}_{0}-0.98 ;{ }^{\mathrm{c}} \mathrm{BJH}$ desorption average pore. 

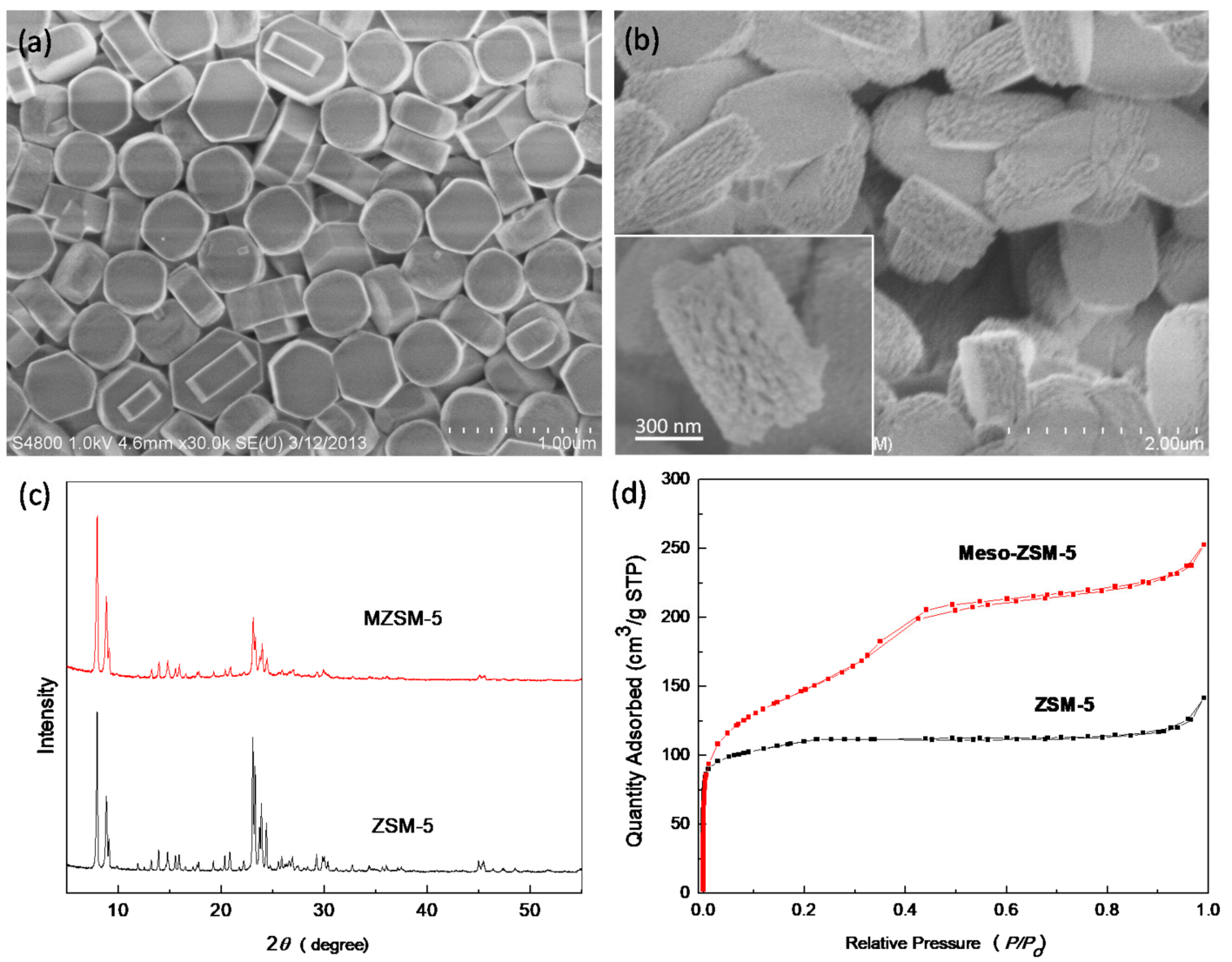

Figure 2. Morphology and texture properties of ZSM-5 zeolites. SEM images of HZSM-5 (a) and FM-HZSM-5 with fin-like mesoporous structure (inset is its high magnification image) (b). XRD patterns (c) and $\mathrm{N}_{2}$ sorption isotherms (d) of FM-HZSM-5 and HZSM-5 zeolites.

The morphology and texture property difference between microporous HY and mesoporous HY (denoted as Meso-HY in later discussions) zeolites that were used in later study were also examined. As shown in Figure $3 a-c$, similar crystal sizes $(400-500 \mathrm{~nm})$ and identical XRD patterns are found for Meso-HY and microporous HY. Unlike FM-ZSM-5 with fin-like mesopores, Meso-HY zeolites show a worm-like mesoporous structure (Figure 3b). Their difference on porous structure is also quantified through $\mathrm{N}_{2}$ adsorption-desorption isotherms. As shown in Figure 3d, conventional microporous HY zeolites present a classic type I adsorption/desorption isotherm for microporous materials, which has only one high uptake at very low relative pressure $\left(\mathrm{P} / \mathrm{P}_{0}<0.02\right)$ and a long plateau towards the highpressure. Meso-HY zeolites, on the other hand, present a steep uptake step at $\mathrm{P} / \mathrm{P}_{0}<0.02$, followed by a slow one afterward on the adsorption/desorption isotherms, a classic combination of both type I and type IV profiles. A hysteresis loop at $0.45<\mathrm{P} / \mathrm{P}_{0}<0.90$ locations suggests the existence of both-end open, mesoporous structure in Meso-HY zeolites. The textural parameters summarized in Table 1 confirm evidentially more accessible surface area of Meso-HY than its microporous counterpart, contributed by the addition of mesopores according to the BET method calculation $\left(766.3 \mathrm{~m}^{2} / \mathrm{g}\right.$ for Meso-HY vs. $720.6 \mathrm{~m}^{2} / \mathrm{g}$ for HY). Although the BET method underestimates the contribution of micropores to the total surface area of zeolites, its accuracy on mesoporous structure measurement confirms the availability of many mesopores in Meso-HY zeolite crystals. For the same reasons (i.e., introduction of mesopores), the calculated pore volume and average $\mathrm{BJH}$ pore size in Meso-HY also significantly increase, as shown in Table 1. 

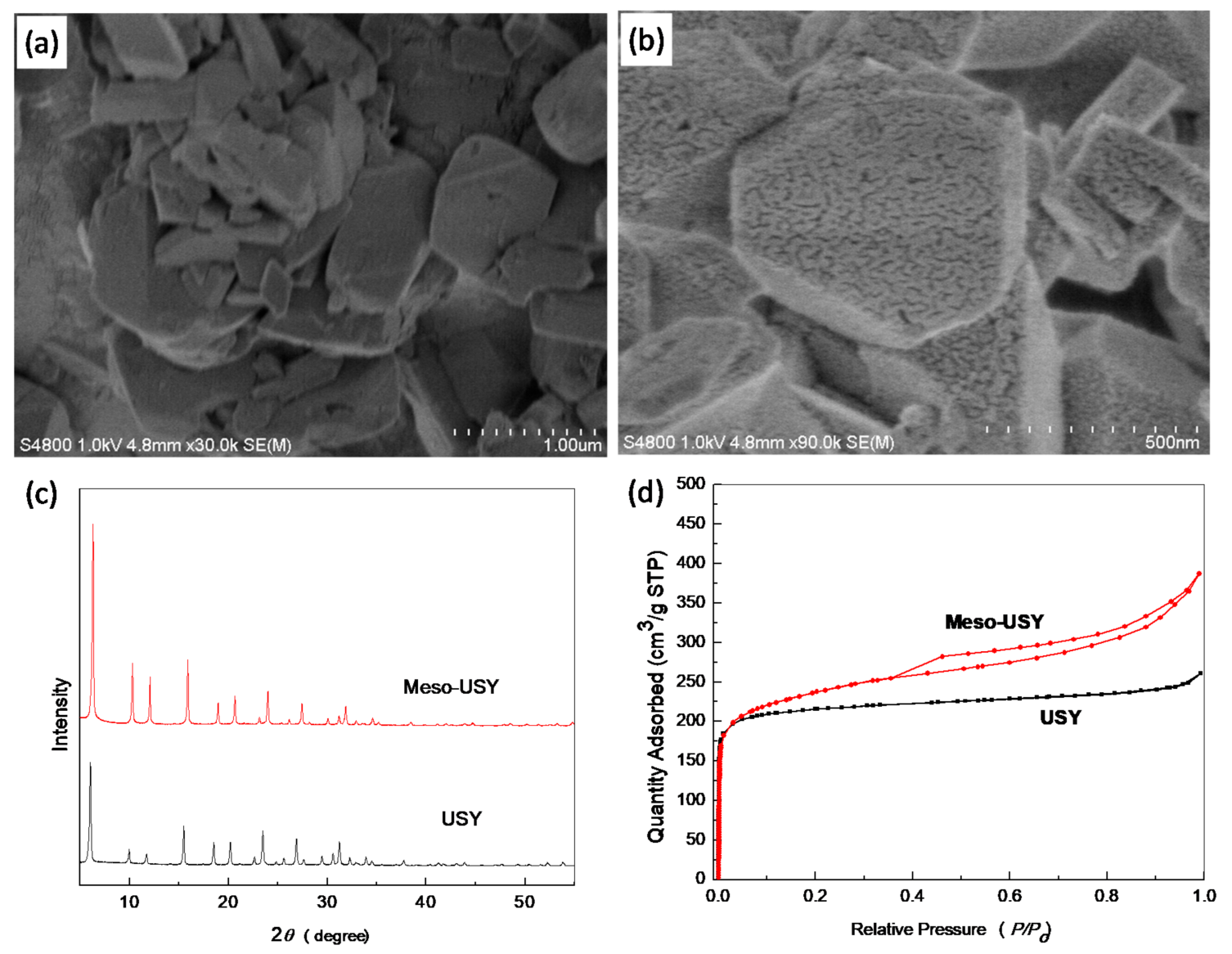

Figure 3. Morphology and texture properties of zeolite Y. SEM images of microporous HY zeolite (a) and Meso-HY zeolite with worm-like mesoporous structure (b). XRD patterns (c) and N2 sorption isotherms (d) of microporous HY and Meso-HY zeolites.

\subsection{Effect of Pore Size and Acidity of Microporous Zeolites in Lignin Depolymerisation}

To investigate how the pore size and acidity of different microporous zeolites affect the depolymerization of Kraft lignin in supercritical ethanol, three types of zeolites, HZSM-5, HBeta, and HY zeolites with exclusive micropores, were used. In addition to the wide adoption of these zeolites in fossil fuel refinery processes, they were chosen in this study in consideration of the fact that HZSM-5 and HY have large differences on both their micropore size (HZSM-5: $5.6 \times 5.3 \AA, 5.5 \times 5.1 \AA$; HY: $7.4 \times 7.4 \AA$ ) and acidity while HBeta carries some micropores comparable to what in HZSM- 5 while others in HY (HZSM-5: $5.6 \times 5.3 \AA$, $5.5 \times 5.1 \AA$; HY: $7.4 \times 7.4 \AA$; HBeta: $7.7 \times 6.6 \AA, 5.6 \times 5.6 \AA$ ), as depicted in Figure 1a. Some similarities on the texture property (BET surface area, pore size, and pore volume) of HBeta with H-ZSM-5 or H-Y are shown in Table 1. The ratio of mediumto-strong solid acidic sites in HBeta is also found similar to what in HY, as shown in Supplementary Figure S1a and Table 2. These shared features allow reasonable, though not ideal, comparison between zeolites with dominated strong acidic sites (HBeta: 0.39; HY: 0.34 ) and those with a more balanced number of the two types of acid sites presents (HZSM5: 1.24). The catalytic depolymerization of Kraft lignin was carried out in a batch reactor for $6 \mathrm{~h}$ after purging with $\mathrm{N}_{2}$ prior to elevating the reaction temperature to $280^{\circ} \mathrm{C}$ and pressure to $8 \mathrm{MPa}$, same as what were used in our previous work [25]. All three types of zeolites exhibit high lignin conversion (65-75\%) with very little char formation, which is also in consistent with previous findings $[6,19,25]$. More than 20 product molecules with a mass weight over 1.0\% were detected by GC-MS in liquid products, as shown in Figure 4a. The early eluted aliphatic products of $\mathrm{C}_{4}-\mathrm{C}_{6}$ in the GC-MS spectra are some short-chain ether 
(e.g., 1,1-diethoxy-ethane as one dominant peak), ester (e.g., ethyl acetate as one dominant peak), alcohols (e.g., butanol as one dominant peak), fatty acid (e.g., acetate), or acetal (e.g., butanal as one dominant peak) that derivate from ethanol reforming reactions [41]. This is verified when comparing with the GC-MS spectrum of lignin ethanolysis products from a blank test involving only ethanol and zeolites at the same reaction conditions (Supplementary Figure S2). Compounds eluted after $7 \mathrm{~min}$, including a few alcohol and ester molecules but most aromatics, appeared only when lignin was added (Supplementary Figure S2). In all ethanolysis samples catalyzed by these three types of microporous zeolites, their product molecules are similar, but the yield and selectivity of individual or grouped compounds were quite different. Signals of the later eluted $\mathrm{C}_{8}-\mathrm{C}_{11}$ compounds were more diversified for samples depolymerized over HBeta and HY than HZSM-5 (Table 3 and Supplementary Figure S2), suggesting that zeolites with higher strong acid percentage (e.g., $\mathrm{HY}$ and HBeta) break down more efficiently both $\mathrm{C}-\mathrm{O}-\mathrm{C}$ (e.g., $\beta-\mathrm{O}-4)$ and $\mathrm{C}-\mathrm{C}$ (e.g., $\beta-1)$ linkages in lignin structure into small phenolic molecules (more discussions are given in Section 2.4). As the dominant products, more aromatics were found in those samples (HZSM-5: 37.4\%; HY: 39.6\%; HBeta: 28.9\%), as shown in Figure 4b-d. Although the strength of strong acidic sites in HZSM- 5 is higher than what in HBeta and HY, their numbers are fewer in HZSM-5, particularly when compared to that in HY. The many weak acidic sites of HZSM- 5 contribute not as effectively as those strong ones to the cracking of lignin structure, which in in consistent with what are observed in hydrocarbon cracking of fossil fuels. Considering the relatively bulky size of lignin fragments and the small size of micropores in these zeolites, the diffusion issues in all three cases are severe as expected. Under such circumstance, the size of micropores seem a more decisive factor than the solid acidity on aromatic production. With both large micropores and a high strong-to-medium acid ratio, samples treated by microporous HY zeolites received the highest yield on phenols and the most diversified aromatic products among the three zeolite types (Table 3 and Supplementary Figure S2). A combination of a similar medium-to-strong acid ratio and some smaller pores seem offset the overall depolymerization efficiency over HBeta zeolites despite their good cracking ability for more small phenols. On the contrary, HZSM- 5 with smaller, but more uniform micropores and a more balanced acid strength achieved more aromatics than HBeta in lignin ethanolysis, though a large percentage of intermediate compounds from incomplete cracking contributed to its comparable aromatics yield as over HY zeolites (more discussions are given in Section 2.4). We admit that the different catalytic activities among these three zeolite types are mixed effects of variations on their crystal structures (i.e., size and shape of membered rings and supercages) and acidic sites (i.e., type, strength, and concentration). Comparisons made between these important cracking zeolites still provide useful insights on how they impact lignin ethanolysis and more general cracking reactions of bulky molecules.

Table 2. Acidity properties of various zeolites used in this study.

\begin{tabular}{|c|c|c|c|c|c|}
\hline Sample & $\mathrm{NaY}$ & $\mathrm{NaNH}_{4} \mathrm{Y}$ & HY & HBeta & HZSM-5 \\
\hline $\begin{array}{l}\text { Weak and medium acid sites, } \mu \text { mold } / g \\
\text { (percentage in total acidity) }\end{array}$ & $\begin{array}{c}71.6 \\
(19.4 \%)\end{array}$ & $\begin{array}{c}365.8 \\
(51.9 \%)\end{array}$ & $\begin{array}{c}249.0 \\
(25.4 \%)\end{array}$ & $\begin{array}{c}208.8 \\
(28.1 \%)\end{array}$ & $\begin{array}{c}644.7 \\
(55.4 \%)\end{array}$ \\
\hline $\begin{array}{l}\text { Strong and ultra-strong acid sites, } \mu \text { mold /g } \\
\text { (percentage in total acidity) }\end{array}$ & $\begin{array}{c}298.2 \\
(80.6 \%)\end{array}$ & $\begin{array}{c}338.5 \\
(48.1 \%)\end{array}$ & $\begin{array}{c}730.6 \\
(74.6 \%)\end{array}$ & $\begin{array}{c}535.4 \\
(71.9 \%)\end{array}$ & $\begin{array}{c}518.4 \\
(44.6 \%)\end{array}$ \\
\hline Total acidity, $\mu$ mold $/ g$ & 369.8 & 704.3 & 979.6 & 744.2 & 1163.1 \\
\hline Medium-to-Strong acid ratio & 0.24 & 0.92 & 0.34 & 0.39 & 1.24 \\
\hline
\end{tabular}


(a)

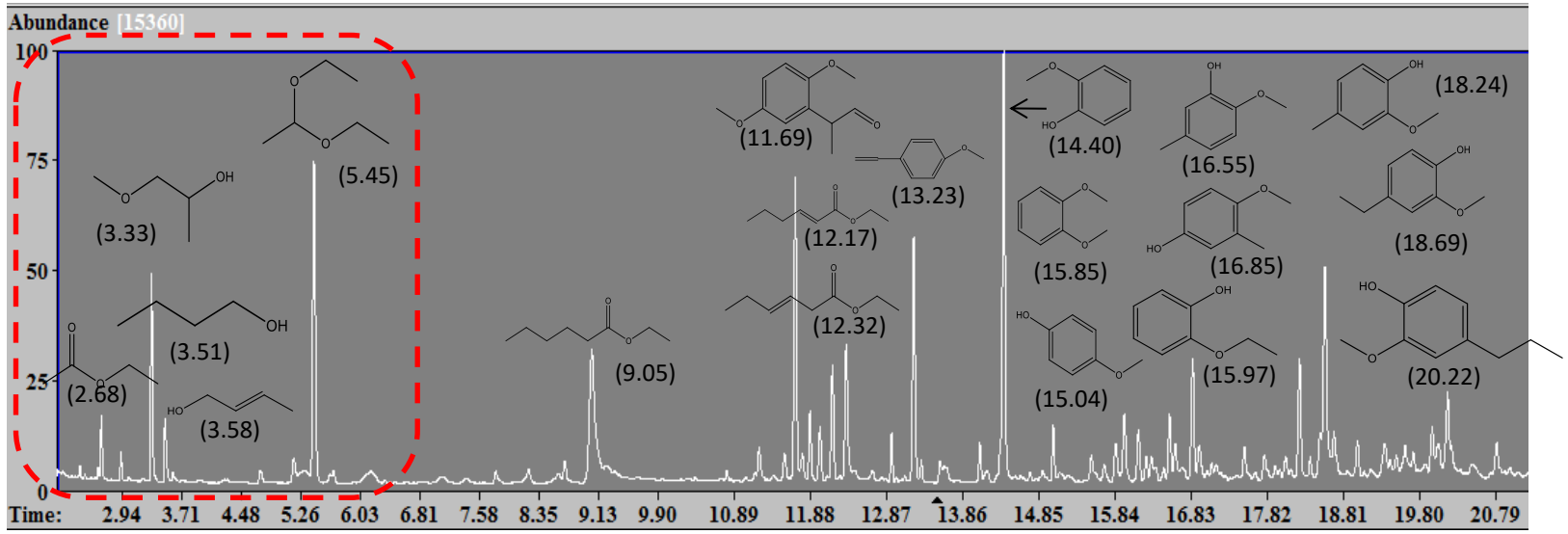

(b)

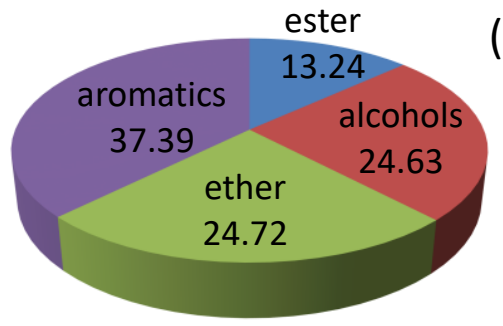

(c)

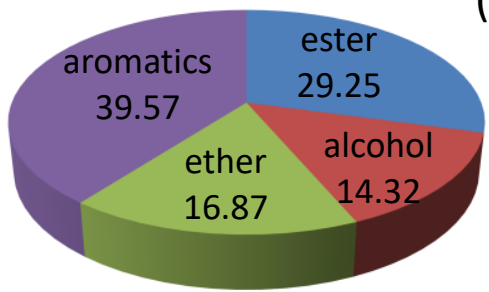

(d)

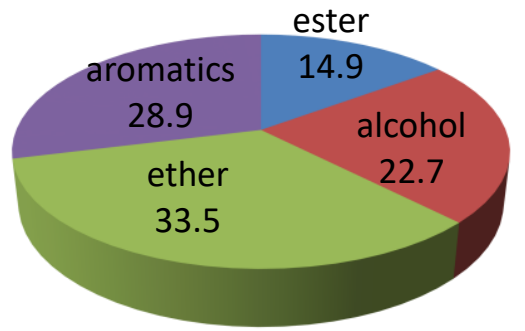

Figure 4. Lignin catalytic depolymerization in supercritical ethanol over different microporous zeolites. (a) GC-MS spectrum of lignin depolymerization products by microporous HY (a) and classified product distributions with (b) HZSM-5, (c) HY, and (d) HBeta zeolites.

Table 3. Aromatics selectivity of lignin depolymerization product over zeolites with microporous and mesoporous structures.

\begin{tabular}{|c|c|c|c|c|c|c|}
\hline \multirow[b]{2}{*}{ Catalyst. } & \multirow[b]{2}{*}{$\begin{array}{l}\text { Aromatics } \\
\text { Selectivity }\end{array}$} & \multicolumn{5}{|c|}{ Main Aromatic Products } \\
\hline & & & & & & Others \\
\hline HBeta & 28.9 & 7.8 & 11.2 & 5.5 & - & 3.4 \\
\hline HY & 39.6 & 17.2 & 10.9 & 5.9 & 2.6 & 3.0 \\
\hline HZSM-5 & 37.4 & 25.4 & 4.2 & 2.5 & 1.3 & 4.0 \\
\hline FM-HZSM-5 & 65.4 & 43.9 & 9.9 & 4.4 & 1.6 & 5.6 \\
\hline Meso-HY & 51.7 & 8.1 & 13.3 & 13.3 & 1.7 & 15.3 \\
\hline
\end{tabular}

\subsection{Zeolites with Different Acidity while Same Micropore Structure in Lignin Depolymerisation}

In aforementioned comparison, though HBeta zeolites share either comparable micropore size or acidity to the other two types of zeolites (i.e., HZSM-5 and HY), respectively, they have framework differences among their crystal structures. To rule out that complexity, we further looked into how solid acidity affects the lignin depolymerization in scEtOH under the same microporous structure of zeolites. As zeolites gain their solid acidity through transformation from sodium type to $\mathrm{H}$ type by multiple ion-exchange processes, we prepared zeolites with different acidity within the same microporous structure by regulating the replacement level of sodium ions in the zeolite crystal structure. Fresh synthesized microporous $\mathrm{Y}$ zeolites were ion-exchanged once (denoted as $\mathrm{NaNH}_{4} \mathrm{Y}$ in later discussions) to serve as zeolites with a lower total acidity than the fully ion-exchanged H-type (denoted as HY) while higher than the original sodium type (denoted as NaY) counterparts. As shown in Table 2 and Supplementary Figure S1b, $\mathrm{NaNH}_{4} \mathrm{Y}$ zeolites 
show more medium acid sites than NaY while fully ion exchanged HY zeolites carry more than double the number of strong acid sites. Over these zeolites, an overal aromatics selectivity of $16.1 \%$ was received in lignin ethanolysis samples using $\mathrm{NaY}$ zeolites, which increases to $29.8 \%$ when using the ion-exchanged once zeolites $\left(\mathrm{NaNH}_{4} \mathrm{Y}\right)$, and to $39.7 \%$ with fully ion-exchanged HY zeolites, respectively (Figure 5a). Among all aromatics, more phenolics are also received with the increase of the total solid acidity of zeolites, no matter such acidity enhancement comes from more medium or strong acidic sites in their crystal structures. Similarly, higher yield on ester is received, accompanied with a decline on alcohol and ether percentages in the liquid product (Figure 5b). This is believed to be the consequence of further transformation of those products with ethanol and acetaldehyde (the first dehydrogenation molecule from ethanol) in acid environment [38]. These results suggest that, with the same micropore structure, an increase on acidity of zeolites, either medium or strong acid strength, promotes the ethanolysis efficiency of lignin and aromatic selectivity in the products.
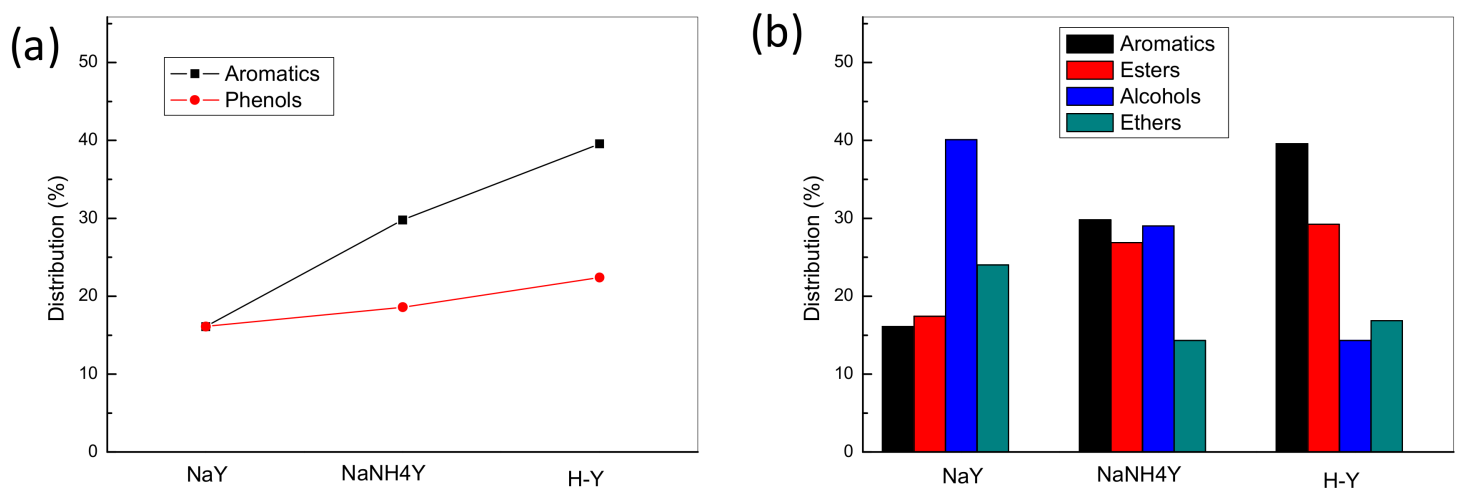

Figure 5. Lignin ethanolysis performance over Y zeolites with different acidity but same microporous structure. (a) Aromatics and phenol, (b) all products distributions.

\subsection{Importance of Mesopores of Zeolites in Lignin Catalytic Depolymerization}

To reveal how mesopores contribute to aromatic yield and selectivity, we compared the catalytic cracking performance of HZSM- 5 and HY zeolites with exclusive micropores and FM-HZSM-5 and Meso-HY that have mesopores in scEtOH lignin depolymerization. As shown in Supplementary Figure S3 and Figure $6 a, b$, signals of compounds of $C_{8}-C_{11}$ eluted later than $7 \mathrm{~min}$ in the GC-MS spectra increase greatly for samples that were depolymerized by FM-HZSM-5 than that using microporous HZSM-5. Although having more diversified products, the dominant compounds include fatty acid esters and aromatics, among which signal increase of the former (i.e., fatty acid) is much less than the latter (i.e., aromatics, mainly phenols). The high yield of aromatics (65.4\% for FM-HZSM-5 versus $37.4 \%$ for HZSM-5) and more diversified aromatic compounds suggest deeper breakdown of lignin fragments over FM-HZSM-5 (Figure 6a,b). Among all aromatic products, 1,2-Dimethoxy-4(1-methoxyethenyl) benzene, a relatively large intermediate aromatic fragment, contributes more than $50 \%$ of all aromatic products over both types of ZSM- 5 zeolites (43.9\% for FMHZSM-5 versus $25.4 \%$ for HZSM-5). Desired phenols including guaiacol and its alkane derivates such as methyl- and ethyl-substituted guaiacols have obviously higher yield over FM-HZSM-5 catalyst ( 21.5\%) than that over microporous HZSM-5 ( 12.0\%), as shown in Table 3. With more aromatics produced, the percentages of alcohol, ester, and ether in the liquid product all decline in samples treated over FM-HZSM-5 zeolites (Figure 6a,b). Like the scEtOH depolymerization over ZSM-5, HY and Meso-HY zeolites contribute similar products of lignin ethanolysis that are assigned to aromatics, ester, alcohol, and ether of $\mathrm{C}_{4}-\mathrm{C}_{12}$. However, the product distribution in each group is quite different: the ether percentage in the liquid product increases despite the yields of alcohol and ester decline 
(Figure $6 c, d)$. This might be the result of quick cleavage of many side groups from lignin fragments at the presence of enriched deprotonated ethanol molecules in supercritical state. As for aromatics, similar yield increase was found (51.7\% for Meso-HY versus 39.6\% for HY) when mesopores were introduced like what happened over ZSM- 5 zeolites, which is accompanied with more diversified individual compounds (Table 3 and Figure $6 c, d$ ).

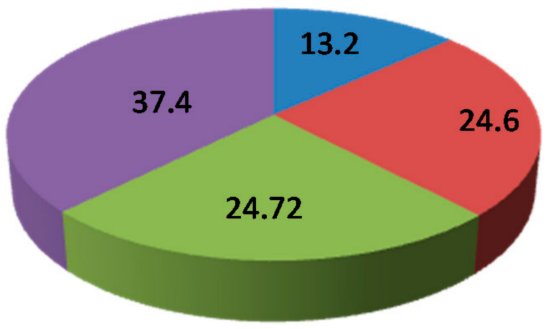

(a)

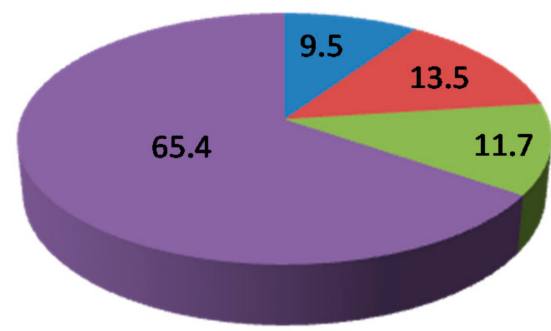

(c)

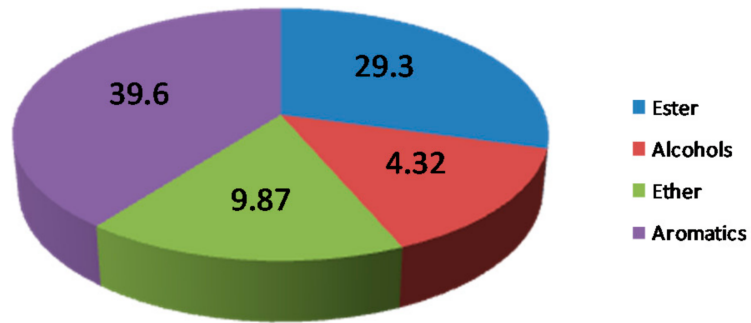

(b)

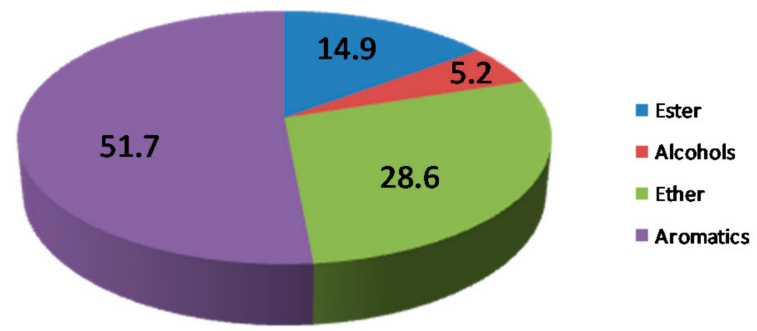

(d)

Figure 6. Classified product distribution of supercritical ethanol depolymerization of lignin over with different zeolites. (a) HZSM-5, (b) FM-HZSM-5, (c) HY, (d) Meso-HY.

As for aromatics, lower yield of gigantic intermediate compounds such as 1,2-Dimethoxy4-(1-methoxyethenyl)benzene were received in samples treated with $\mathrm{Y}$ zeolites when compared to what happened over HZSM-5 zeolites (HY: 17.2\%; Meso-Y: 8.1\% vs. HZSM-5: 25.4\%; FM-HZSM-5: 43.9\%), as shown in Table 3. More small phenols were also found in the ethanolysis products over Y zeolites (HY: 22.4\%, Meso-Y: 37\% vs. HZSM-5: 12.0\%, FM-HZSM-5: 21.5\%). This suggests that excessive strong acid sites of HY zeolites promotes cleavage of not just the ether linkages (e.g., $\beta-\mathrm{O}-4$ bonds) on the benzene ring, but also the $\mathrm{C}-$ $C$ linkages (e.g., $\beta-1$ bonds), particularly those connecting benzene rings and fatty acid side groups like para-adamantaneacetic acid in 1,2-Dimethoxy-4-(1-methoxyethenyl)benzene. This finding is consistent with observations involving other zeolites with a high percentage of strong acid sites. For examples, in Table 3, for ethanolysis samples using HBeta and HY, their yield of 1,2-Dimethoxy-4-(1-methoxyethenyl)benzene is lower than that using HZSM-5 (HY: 17.2\%, HBeta: 7.8\%, HZSM-5: 25.4\%). As the consequence, more phenols (i.e., guaiacol and alkane substituted guaiacols) were released from lignin structure over those zeolites (Table 3 and Supplementary Figure S1). As the consequence, in products of those samples, the percentage of $\mathrm{C}_{8}-\mathrm{C}_{11}$ fatty ethers or esters formed from the cleaved side groups are also found much higher (Supplementary Figure S1). Within mesoporous zeolites, Meso-HY produces more phenol compounds and has higher yields for many of them in the ethanolysis products of lignin when compared to FM-HZSM-5 zeolites that have unique fin-like mesoscale pathways but more balanced acidic strength (Table 3).

\section{Discussion}

Generally speaking, micropores defined by the crystal framework of zeolites are too small for lignin, whose radius of gyration is about several nanometers in aqueous solutions [42]. Even after initial degradation in scEtOH, it is still difficult for fragments of lignin 
and its excessive intermediate oligomers or monomers to diffuse deep in zeolite crystals to interact with numerous acidic sites there [33]. This causes those giant molecules to exclusively accumulate near the entrance of micropores close to zeolite surface to form coke and eventually block those diffusion pathways [32,36,43,44]. As the consequence, slow deactivation of the zeolite catalyst occurs, just like what happens in fossil fuel cracking processes [45]. Mesoporous zeolites or zeolites with a transport pathway network comprised of pores at different scales (i.e., hierarchical pore structure) are therefore necessary to improve the diffusion of bulky reactants or products inside zeolites [33]. Even though the introduction of mesopores might reduce the surface area contributed by micropores if such space was originally part of the zeolite framework, their presence provides more accessible surface area: not only the new surface area created by mesopores, but also more accessible surface from micropores deep inside zeolite crystal. In addition, the availability of mesopores also helps expose and utilize more acidic active sites inside zeolite crystals.

The results on higher phenol selectivity over mesoporous zeolites (e.g., FM-HZSM-5 and Meso-HY) confirm their capability of deep breakdown of lignin compared to their microporous counterparts. Their unique textural features promote the lignin depolymerization from two aspects: (i) their many mesoscale pathways significantly reduce the diffusion resistance for large molecules to reach and leave the connected micropores in zeolite crystal to avoid pore blocking and coke formation; (ii) an open hierarchical pore configuration also helps expose more crystal surface, micropores, and the acidic sites inside zeolite crystal, making them accessible to bulky molecules (e.g., partial depolymerized, intermediate molecules) so that they can interact with the active sites of zeolites and further break them down to small molecules (e.g., phenols) before leaving zeolite surface. The synergetic effect of these two key factors indeed leads to higher selectivity of major phenols in products of lignin ethanolysis over mesoporous zeolites such as Meso-HY. Our study finds that the classic knowledge on zeolites-strong acid sites and high acidity promote the breakdown of large fragments-is still valid in scEtOH depolymerization of lignin despite that EtOH is believed to be deprotonated already and enriched over zeolites [13]. The availability of mesopores is also beneficial for the reception of smaller phenols instead of large aromatic fragments. As a result of the reaction complexity of lignin depolymerization in scEtOH (e.g., the participation of scEtOH in the cracking reactions [41]), the change on product distribution seems less sensitive to mesopores of various shapes when compared to the impact from the total acidity and the ratio of medium-tot-strong acidic sites of zeolites. With the diffusion of gigantic molecules less restricted to reach the surface of zeolites, the number of the acidic sites and acidic strength there decide the eventual cracking level of lignin and the fate of its large intermediate compounds before leaving the catalyst surface: higher acidity and/or strong-to-medium acid ratio promote more aromatics from lignin cracking in scEtOH.

\section{Materials and Methods}

\subsection{Materials}

Tetrapropyl ammonium hydroxide $\left(\mathrm{TPAOH}, 1 \mathrm{M}\right.$ in $\left.\mathrm{H}_{2} \mathrm{O}\right)$, sodium aluminate $\left(\mathrm{NaAlO}_{2}\right.$, $\sim 8 \% \mathrm{H}_{2} \mathrm{O},>99 \%$ ), aluminum iso-propoxide (AlP), tetramethylammonium hydroxide (TMAOH, $25 \%$ aqueous solution), tetraethylorthosilicate (TEOS, $>99 \%)$, sodium hydroxide $(\mathrm{NaOH})$ pellets, ethanol $\left(\mathrm{C}_{2} \mathrm{H}_{5} \mathrm{OH},>99.5 \%\right)$, Dimethyloctadecyl [3-(trimethoxysilyl)propyl]ammonium chloride (TPOAC), and cetrimonium bromide (CTAB, >99\%) were purchased from SigmaAldrich (St. Louis, MO, USA) and used as received without further purification. Mesoporous HY zeolites (CBV 720) were purchased from Zeolyst, Inc (Conshohocken, PA, USA) with a $\mathrm{SiO}_{2} / \mathrm{Al}_{2} \mathrm{O}_{3}$ ratio of 30 .

\subsection{Zeolite Synthesis}

\subsubsection{ZSM-5 and Fin-like Mesoporous ZSM-5 Synthesis}

For fin-like mesoporous zeolite FM-ZSM-5 synthesis, TEOS, $\mathrm{NaAlO}_{2}$, and TPAOH were firstly added under vigorous stirring with a pre-calculated ratio of TPOAC and CTAB 
until a clear solution was obtained. The final molar composition of synthesized solution was $\mathrm{SiO}_{2}: \mathrm{Al}_{2} \mathrm{O}_{3}$ : TPAOH: TPOAC: CTAB: $\mathrm{H}_{2} \mathrm{O}=1$ 15: 0.25: 6.0: 0.6: 2400. The mixture was further stirred for $2 \mathrm{~h}$ at room temperature and then transferred to Teflon lined autoclaves and kept at $150{ }^{\circ} \mathrm{C}$ for $48 \mathrm{~h}$. After crystallization, the solid product was separated by centrifugation at the speed of $2000 \mathrm{rpm}$ for $10 \mathrm{~min}$. The received zeolites were further washed several times with distilled water, dried over night at $120^{\circ} \mathrm{C}$, and calcined in air at $550{ }^{\circ} \mathrm{C}$ for $8 \mathrm{~h}$. The conventional microporous zeolite ZSM-5 was also synthesized through a similar hydrothermal process, but without adding TPOAC and CTAB.

\subsubsection{Y Zeolites Synthesis}

Zeolite $\mathrm{Y}$ was prepared followed a modified method reported by Mintova et al. [46]. A solution of $0.05 \mathrm{~N} \mathrm{NaOH}$ was first prepared and TMAOH and AIP were then added in the same order under vigorous agitation until a clear solution was formed. TOES was then added drop wise and the mixture was aged for 3 days under vigorous stirring at room temperature. This gives a final molar composition of $\mathrm{SiO}_{2}: \mathrm{Al}_{2} \mathrm{O}_{3}: \mathrm{Na}_{2} \mathrm{O}:(\mathrm{TMA})_{2} \mathrm{O}$ : $\mathrm{H}_{2} \mathrm{O}=1$ : 0.29: 0.0094: 0.72: 108.82. After loading in the aged solution, the Teflon-lined stainless-steel autoclave was sealed and kept at $100{ }^{\circ} \mathrm{C}$ for 6 days. After crystallization, the solid product was recovered by centrifugation and further washed with DI water, dried overnight, and calcined in air.

\subsubsection{Beta Zeolites Synthesis}

Zeolite Beta was prepared following a modified method reported by Camblor et al. [47]. TEOS, $\mathrm{NaAlO}_{2}$, and TEAOH were firstly added under vigorous stirring until a clear solution was obtained. The final molar composition of synthesized solution was $\mathrm{SiO}_{2}$ : $\mathrm{Al}_{2} \mathrm{O}_{3}$ : TEAOH: $\mathrm{H}_{2} \mathrm{O}=1.0: 0.015: 0.56: 30$. The mixture was placed in a Teflon-lined stainless-steel autoclave and kept at $140^{\circ} \mathrm{C}$ for $60 \mathrm{~h}$. After crystallization, the solid product was recovered by centrifugation and further washed with DI water, dried overnight, and calcined in air. The morphology and crystal structure of synthesized Beta zeolites are given in Supplementary Figure S4.

\subsubsection{Ion-Exchange and H-type Zeolites Preparation}

All received sodium type zeolites were first dried and calcined in air at $550{ }^{\circ} \mathrm{C}$ for $8 \mathrm{~h}$. They were then ion-exchanged three times with a $0.1 \mathrm{M} \mathrm{NH}_{4} \mathrm{NO}_{3}$ solution at $90{ }^{\circ} \mathrm{C}$ for 90 min with a liquid/solid ratio of $10 \mathrm{~cm}^{3} / \mathrm{g}$ under magnetic agitation (500 rpm). The solid was further separated, extensively washed with DI water, and dried over night at $120^{\circ} \mathrm{C}$. The dried zeolite samples were finally calcined at $550{ }^{\circ} \mathrm{C}$ for $6 \mathrm{~h}$ with a temperature ramp rate of $1.5^{\circ} \mathrm{C} / \mathrm{min}$ to receive $\mathrm{H}$-type zeolites.

\subsection{Characterization}

Scanning electron microscopy (SEM) images were taken on a Hitachi S-4800. Samples were prepared by dusting the zeolite powder onto double sided carbon tape and mounted on an alumina stub. All samples were subsequently sputter coated with a thin gold film to reduce charge effect.

X-ray diffraction (XRD) analysis was done on a Bruker D8 diffractometer, using $\mathrm{Cu}-\mathrm{K} \alpha$ radiation at room temperature and instrumental settings of $40 \mathrm{kV}$ and $40 \mathrm{~mA}$. Data were recorded in the $2 \theta$ range of $6-55^{\circ}$ with an angular step size of $0.02^{\circ}$.

Nitrogen adsorption isotherms were obtained at $-196^{\circ} \mathrm{C}$ on a Micromeritics ASAP 2020 Surface Area and Porosity Analyzer in a relative pressure range from 0.05 to 0.99 . Before measurement, samples were degassed at $300{ }^{\circ} \mathrm{C}$ for $6 \mathrm{~h}$. The pore size distribution was calculated using the Nonlocal Density Functional Theory (NLDFT) method from the adsorption branch.

In $\mathrm{NH}_{3}$-TPD program, samples were pretreated with helium gas at $500{ }^{\circ} \mathrm{C}$ for $1 \mathrm{~h}$. After being cooled to the adsorption temperature $\left(50^{\circ} \mathrm{C}\right)$, samples adsorbed $\mathrm{NH}_{3}$ for $30 \mathrm{~min}$, followed by purging with helium gas for $30 \mathrm{~min}$ at $120^{\circ} \mathrm{C}$. After the baselines were 
stabilized, sample temperature was elevated at a constant heating rate of $10{ }^{\circ} \mathrm{C} / \mathrm{min}$ to $800{ }^{\circ} \mathrm{C}$ in helium flow $(30 \mathrm{~mL} / \mathrm{min})$ and the corresponding $\mathrm{NH}_{3}-\mathrm{TPD}$ desorption profiles were recorded.

\subsection{Lignin Depolymerisation Tests}

The catalytic conversion of Kraft lignin was carried out at $280{ }^{\circ} \mathrm{C}$ for $6 \mathrm{~h}$ in a highpressure batch reactor (Col-Int Tech, $200 \mathrm{~mL}$ ). For each run, $1.0 \mathrm{~g}$ lignin, $0.5 \mathrm{~g}$ catalyst, and $100 \mathrm{~mL}$ ethanol were first loaded in the reactor and the sealed reactor was then evacuated and purged with high-purity nitrogen gas for three times at room temperature. The reactor temperature was then risen to $280{ }^{\circ} \mathrm{C}$ with the reactor pressure reaching $\sim 8 \mathrm{MPa}$. After the reaction was carried out for $6 \mathrm{~h}$, the liquid was filtered and taken for product identification and analysis on a gas chromatography-mass spectrometry (GC-MS) instrument (Agilent 7890A-5975C). Benzyl alcohol (0.1 vol\% in ethanol, $1.0 \mu \mathrm{L})$ was added in the product samples $(1 \mathrm{~mL})$ before GC-MS analysis, serving as the known internal standard in GC-MS spectra to normalize the peak area for each compound. Multiple-point internal standard plots were generated, covering the expected concentration range of major product compounds. For those commercially available compounds, such as 4-methyl phenol (i.e., cresol) and 2-methoxy-phenol (i.e., guaiacol), diluted solutions with known concentrations were prepared. For other commercially-not-available compounds such as 3-methyl-1- adamantaneacetic acid, the lignin depolymerization product obtained from different catalysts was mixed and further concentrated by evaporating most ethanol using a rotary evaporator. The obtained liquid was then diluted with ethanol to get different concentrations of each compound using benzyl alcohol as the internal standard (0.8 $\mathrm{mM})$. Plots of the peak area ratio of several major aromatic compounds in lignin depolymerization products to the internal standard (benzyl alcohol) were made versus the concentration ratio [25]. The original concentrations of those commercially-not-available compounds in the mother solution were determined by their area ratios to guaiacol whose concentration in samples was found through their own multiple-point internal standard curve. Yield of an individual compound (or grouped products) is calculated by its weight obtained from GC-MS data and its selectivity as the yield percentage of all products. The lignin conversion was calculated based on the weight difference between initial solid added to the batch reactor (lignin + zeolites) and solid leftover after reaction (lignin residue + zeolites), which was divided by the weight of lignin added in each run $(\sim 0.5 \mathrm{~g})$.

\section{Conclusions}

In summary, we examined how acidity and pore structure of different zeolites affect lignin depolymerization in supercritical ethanol. Zeolites with various micropore size or acidity defined by their crystal structures were first used to evaluate the roles of these two important factors on lignin depolymerization. Zeolites with same microporous structure, but different acidity caused by various ion-exchange degrees were further evaluated, followed by zeolites with similar acidity but different pore sizes (i.e., mesoporous zeolites versus and microporous counterparts of HZSM-5 and HY zeolites). Despite the reaction complexity of lignin depolymerization and its greatly diversified products, similar lignin conversion (60-75\%) and comparable aromatics selectivity (30-40\%) were achieved for microporous zeolites used in this study when compared to other reported data. As the first work using mesoporous zeolites in lignin ethanolysis, higher aromatics selectivity was achieved on both zeolite types (FM-HZSM-5: 65.4\%; Meso-HY: 51.7\%). Moreover, higher strong-to-medium acid ratios in HBeta and HY was found effective to cleave both $\mathrm{C}-\mathrm{O}-\mathrm{C}$ and $\mathrm{C}-\mathrm{C}$ linkages in lignin structure to receive more phenols while HZSM-5 with more medium acid sites break down mainly the ether bonds. A hierarchically porous structure is important to promote mass transport and the exposure and utilization of those acidic sites inside zeolites like in many petrochemical reactions involving bulky molecules. When the diffusion issues become less severe for bulky lignin and its partially decomposed intermediate and monomer compounds in mesoporous zeolites, the acidity 
factor dominantly decides the yield and selectivity of products in lignin ethanolysis. These findings provide important insights on the selection and design of zeolites with appropriate acidity and pore structure to facilitate lignin depolymerization in supercritical ethanol, which will help not only eliminate this high-volume farm waste and environmental hazard of paper and pulp plants, but also promote the utilization efforts on converting its rich aromatic units into important chemicals and fuels. The same knowledge may also benefit other catalytic cracking processes using a variety of heating and/or solvent assistance to improve the conversion, yield, and selectivity of bulky hydrocarbons.

Supplementary Materials: The following are available online at https: / /www.mdpi.com/2073-4 $344 / 11 / 2 / 270 /$ s1, Figure S1: $\mathrm{NH}_{3}$-TPD profiles of various types of zeolites (a) and different ionexchange degrees of microporous $\mathrm{Y}$ zeolites (b), Figure S2: GC-MS spectra of lignin depolymerization in supercritical ethanol with microporous HBeta (a), HZSM-5 (b), HY (c), and a blank test (with only ethanol and HZSM-5, no lignin), Figure S3: GC-MS spectra of lignin depolymerization in supercritical ethanol with mesoporous FM-HZSM-5 (a) and microporous HZSM-5 zeolites, Figure S4: SEM image and XRD spectrum of HBeta zeolites.

Author Contributions: Conceptualization, Y.Z. and S.W.; methodology, N.C.B., Y.W., H.B., Y.Z. and S.W.; validation, N.C.B., Y.W., H.H., Y.L. and H.B.; formal analysis, N.C.B., Y.W., Y. Z., S.W.; resources, H.B., Y.Z. and S.W.; writing-original draft preparation, N.C.B., Y.W., Y.Z. and S.W.; writing-review and editing Y.Z. and S.W.; supervision, S.W.; funding acquisition, S.W. All authors have read and agreed to the published version of the manuscript.

Funding: This research was funded by ACS Petroleum Research Fund [58598-ND10], Louisiana Board of Regent, ITRS [LEQSF(2018-19)-RD-D-04], and Louisiana Harrelson Family Professorship.

Data Availability Statement: All experimental data of this study are stored and available from S.W. for sharing upon request unless it may lead to the copyright violations from the publishers or other organizations.

Conflicts of Interest: The authors declare no conflict of interest.

\section{References}

1. Zakzeski, J.; Bruijnincx, P.C.A.; Jongerius, A.L.; Weckhuysen, B.M. The catalytic valorization of lignin for the production of renewable chemicals. Chem. Rev. 2010, 110, 3552-3599. [CrossRef]

2. Carrott, P.J.M.; Carrott, M.R. Lignin—from natural adsorbent to activated carbon: A review. Bioresour. Technol. 2007, 98, 2301-2312. [CrossRef] [PubMed]

3. Ragauskas, A.J.; Williams, C.K.; Davison, B.H.; Britovsek, G.; Cairney, J.; Eckert, C.A.; Frederick, W.J.; Hallett, J.P., Jr.; Leak, D.J.; Liotta, C.L.; et al. The path forward for biofuels and biomaterials. Science 2006, 311, 484-489. [CrossRef] [PubMed]

4. Ragauskas, A.J.; Beckham, G.T.; Biddy, M.J.; Chandra, R.; Chen, F.; Davis, M.F.; Davison, B.H.; Dixon, R.A.; Gilna, P.; Keller, M.; et al. Lignin valorization: Improving lignin processing in the biorefinery. Science 2014, 344, 1246843. [CrossRef] [PubMed]

5. Patil, P.T.; Armbruster, U.; Martin, A. Heterogeneously catalyzed hydroprocessing of organosolv lignin in sub- and supercritical solvents. Energy Fuel 2011, 25, 4713-4722. [CrossRef]

6. Ma, R.; Hao, W.; X. Ma, X.; Tian, Y.; Li, Y. Catalytic Ethanolysis of kraft lignin into high-value small-molecular chemicals over a nanostructured $\alpha$-molybdenum carbide catalyst. Angew. Chem. Int. Ed. 2014, 53, 7310-7315. [CrossRef]

7. Staerk, K.; Taccardi, N.; Boesmann, A.; Wasserscheid, P. Oxidative depolymerization of lignin in ionic liquids. ChemSusChem 2010, 3, 719-723. [CrossRef]

8. Caballero, J.A.; Font, R.; Marcilla, A. A Study of the primary pyrolysis of Kraft lignin at high heating rates: Yields and kinetics. J. Anal. Appl. Pyrolysis 1996, 36, 159-178. [CrossRef]

9. Ferdous, D.; Dalai, A.K.; Bej, S.K.; Thring, R.W. Pyrolysis of lignins: Experimental and kinetics studies. Energy Fuel 2002, 16, 1405-1412. [CrossRef]

10. Wang, X.; Rinald, R. Solvent effects on the hydrogenolysis of diphenyl ether with Raney nickel and their implications for the conversion of lignin. ChemSusChem 2012, 5, 1455-1466. [CrossRef]

11. Albano, G.; Evangelisti, C.; Aronica, L.A. Hydrogenolysis of benzyl protected phenols and aniline promoted by supported palladium nanoparticles. Chem. Sel. 2017, 2, 384-388. [CrossRef]

12. Song, Q.; Wang, F.; Cai, J.; Wang, Y.; Zhang, J.; Yu, W.; Xu, J. Lignin depolymerization (LDP) in alcohol over nickel-based catalysts via a fragmentation-hydrogenolysis process. Energy Environ. Sci. 2013, 6, 994-1007.

13. Guvenatam, B.; Geeres, E.H.; Pidko, E.A.; Hensen, E.J. Lewis acid catalyzed depolymerization of soda lignin in supercritical ethanol/water mixtures. Catal. Today 2016, 269, 9-20. [CrossRef]

14. Thring, R.W.; Breau, J. Hydrocracking of solvolysis lignin in a batch reactor. Fuel 1996, 75, 795. [CrossRef] 
15. Yan, N.; Zhao, C.; Dyson, P.J.; Wang, C.; Liu, L.; Kou, Y. Selective degradation of wood lignin over noble-metal catalysts in a two-step process. ChemSusChem 2008, 1, 626-629. [CrossRef] [PubMed]

16. Roberts, V.M.; Stein, V.; Reiner, T.; Lemonidou, A.; Li, X.; Lercher, J.A. Towards quantitative catalytic lignin depolymerization. Chem. Eur. J. 2011, 17, 5939-5948. [CrossRef]

17. Laskar, D.D.; Tucker, M.P.; Chen, X.; Helms, G.L.; Yang, B. Noble-metal catalyzed hydrodeoxygenation of biomass-derived lignin to aromatic hydrocarbons. Green Chem. 2014, 16, 897-910. [CrossRef]

18. Toledano, A.; Serrano, L.; Labidi, J.; Pineda, A.; Mariana Balu, A.; Luque, R. Heterogeneously catalysed mild hydrogenolytic depolymerisation of lignin under microwave irradiation with hydrogen-donating solvents. ChemCatChem 2013, 5, 977-985. [CrossRef]

19. Warner, G.; Hansen, T.S.; Riisager, A.; Beach, E.S.; Barta, K.; Anastas, P.T. Depolymerization of organosolv lignin using doped porous metal oxides in supercritical methanol. Bioresour. Technol. 2014, 161, 78-83. [CrossRef]

20. Margellou, A.; Triantafyllidis, K. Catalytic transfer hydrogenolysis reactions for lignin valorization to fuels and chemicals. Catalysts 2019, 9, 43. [CrossRef]

21. Yamaguchi, A.; Watanabe, T.; Saito, K.; Kuwano, S.; Murakami, Y.; Mimura, N.; Sato, O. Direct conversion of lignocellulosic biomass into aromatic monomers over supported metal catalysts in supercritical water. Mol. Catal. 2019, 477, 110557. [CrossRef]

22. Barta, K.; Matson, T.D.; Fettig, M.L.; Scott, S.L.; Iretskii, A.V.; Ford, P.C. Catalytic disassembly of an organosolv lignin via hydrogen transfer from supercritical methanol. Green Chem. 2010, 12, 1640-1647. [CrossRef]

23. Yan, F.; Ma, R.; Ma, X.; Cui, K.; Wu, K.; Chen, M.; Li, Y. Ethanolysis of Kraft lignin to platform chemicals on a MoC 1-x /Cu-MgAlO z catalyst. Appl. Catal. B Environ. 2017, 202, 305-313. [CrossRef]

24. Jeong, S.; Yang, S.; Kim, D.H. Depolymerization of Protobind lignin to produce monoaromatic compounds over Cu/ZSM-5 catalyst in supercritical ethanol. Mol. Catal. 2017, 442, 140-146. [CrossRef]

25. Wang, Y.; Song, J.; Baxter, N.; Kuo, G.T.; Wang, S. Synthesis of hierarchical ZSM-5 zeolites by solid-state crystallization and their catalytic properties. J. Catal. 2017, 349, 53-65. [CrossRef]

26. Sharma, R.K.; Bakhshi, N.N. Catalytic upgrading of pyrolysis oil. Energy Fuels 1993, 7, 306-314. [CrossRef]

27. Zhao, C.; Lercher, J.A. Selective hydrodeoxygenation of lignin-derived phenolic monomers and dimmers to cycloalkanes on $\mathrm{Pd} / \mathrm{C}$ and HZSM-5 catalysts. ChemCatChem 2012, 4, 64-68. [CrossRef]

28. Deepa, A.K.; Dhepe, P.L. Lignin depolymerisation into aromatic monomers over solid acid catalysts. Acs Catal. 2015, 5, 365-379. [CrossRef]

29. Han, H.; Li, J.; Wang, H.; Han, Y.; Chen, Y.; Li, J.; Zhang, Y.; Wang, Y.; Wang, B. One-Step valorization of calcium lignosulfonate to produce phenolics with the addition of solid base oxides in the hydrothermal reaction system. Energy Fuels 2019, 9, b00332. [CrossRef]

30. Wang, W.; Luo, Z.; Li, S.; Xue, S.; Yang, Y. Effects of the controllable mesostructure of nano-sized ZSM-5 on the co-cracking of phenolic bio-oil model compounds and ethanol. Catal. Sci. Technol. 2019, 9, 3525-3536. [CrossRef]

31. Zhou, M.; Sharma, B.K.; Li, J.; Zhao, J.; Xu, J.; Jiang, J. Catalytic valorization of lignin to liquid fuels over solid acid catalyst assisted by microwave heating. Fuel 2019, 239, 239-244. [CrossRef]

32. Liao, W.; Wang, X.; Li, L.; Fan, D.; Wang, Z.; Chen, Y.; Li, Y.; Xie, X. Catalytic alcoholysis of lignin with HY and ZSM-5 zeolite catalysts. Energy Fuels 2020, 34, 599-606. [CrossRef]

33. Corma, A. From microporous to mesoporous molecular sieve materials and their use in catalysis. Chem. Rev. 1997, 97, 2373-2420. [CrossRef] [PubMed]

34. Jiang, J.; Yu, J.; Corma, A. Extra-Large-Pore zeolites: Bridging the gap between micro and mesoporous structures. Angew. Chem. Int. Ed. 2010, 49, 3120-3145. [CrossRef]

35. Wang, Y.; Fang, Y.; He, T.; Hu, H.; Wu, J. Hydrodeoxygenation of dibenzofuran over noble metal supported on mesoporous zeolite. Catal. Comm. 2011, 12, 1201-1205. [CrossRef]

36. Wang, Y.; He, T.; Liu, K.; Wu, J.; Fang, Y. From biomass to advanced bio-fuel by catalytic pyrolysis/hydro-processing: Hydrodeoxygenation of bio-oil derived from biomass catalytic pyrolysis. Bioresour. Technol. 2012, 108, 280-284. [CrossRef] [PubMed]

37. Chen, L.; Li, X.; Rooke, J.C.; Zhang, Y.; Yang, X.; Tang, Y.; Xiao, F.; Su, B. Hierarchically structured zeolites: Synthesis, mass transport properties and applications. J. Mater. Chem. 2012, 22, 17381-17403. [CrossRef]

38. He, T.; Wang, Y.; Miao, P.; Li, J.; Wu, J.; Fang, Y. Hydrogenation of naphthalene over noble metal supported on mesoporous zeolite in the absence and presence of sulfur. Fuel 2013, 106, 365-371. [CrossRef]

39. Wang, Y.; Wu, J.; Wang, S. Hydrodeoxygenation of bio-oil over Pt-based supported catalysts: Importance of mesopores and acidity of the support to compounds with different oxygen contents. Rsc Adv. 2013, 3, 12635-12640. [CrossRef]

40. Zhao, Y.; Li, S.; Wang, Z.; Wang, S.; Wang, S.; Ma, X. New ZnCe catalyst encapsulated in SBA-15 in the production of 1,3-butadiene from ethanol. Chin. Chem. Lett. 2020, 31, 535-538. [CrossRef]

41. Ma, X.; Ma, R.; Hao, W.; Chen, M.; Yan, F.; Cui, K.; Tian, Y.; Li, Y. Common pathways in ethanolysis of kraft lignin to platform chemicals over molybdenum-based catalysts. Acs Catal. 2014, 5, 4803-4813. [CrossRef]

42. Vaino, U.; Maximova, N.; Hortling, B.; Laine, J.; Stenius, P.; Simola, L.; Gravitis, J.; Serimaa, R. Morphology of dry lignins and size and shape of dissolved kraft lignin particles by X-ray scattering. Langmuir 2004, 20, 9736-9744. [CrossRef]

43. Wang, Y.; Huang, H.; Baxter, N.C.; Liao, Y.; Zhao, Y.; Wang, S. Guaiacol hydrodeoxygenation over Pd catalyst with mesoporous ZSM-5 support synthesized by solid-state crystallization. Catal. Today 2020, 358, 60-67. [CrossRef] 
44. Rezaei, P.; Shafaghat, H.; Daud, W. Production of green aromatics and olefins by catalytic cracking of oxygenate compounds derived from biomass pyrolysis: A review. Appl. Catal. A 2014, 469, 490-511. [CrossRef]

45. Argyle, M.; Bartholomew, C. Heterogeneous catalyst deactivation and regeneration: A review. Catalysts 2015, 5, 145-269. [CrossRef]

46. Mintova, S.; Olson, N.H.; Bein, T. Electron Microscopy Reveals the Nucleation Mechanism of Zeolite Y from Precursor Colloids. Angew. Chem. Int. Ed. 1999, 38, 3201-3204. [CrossRef]

47. Camblor, M.A.; Corma, A.; Mifsud, A.; Pérez-Pariente, J.; Valencia, A. Synthesis of nanocrystalline zeolite beta in the absence of alkali metal cations. Stud. Surf. Sci. Catal. 1997, 105, 341. 